\title{
Impact of Physical Activity on the Aggressiveness, Deviant Behavior and Self-esteem with School Children Aged 11-15
}

\author{
Georgi Georgiev ${ }^{1}$, Serjozha Gontarev ${ }^{1}$ \\ 'University St. Cyril and Methodius, Faculty for Physical Education, Sport, and Health, Skopje, North Macedonia
}

\begin{abstract}
Comprehension of factors responsible for reduction of physical activities with adolescents is of a primary importance for an effective development of programs and strategies in promoting the physical activity among this population group. The aim of the present research is the explore impact of physical and sports activities on the aggressive, deviant behavior and self-confidence among schoolchildren aged from 11 to 15 . The research was conducted on a sample of 177 Macedonian adolescents from several primary schools in the city of Skopje. More scales of assessing physical activity, sedentary habits, self-confidence and behaving aggressively and in a deviant way were applied for the purposes of the present research. The results obtained from the research are statistically processed and each variable is with individually calculated basic descriptive statistic, while the relation between the applied variables is determined by the use of Pearson's coefficient of correlation (R). On the base of the obtained data a conclusion can be drawn that there is no statistically significant relation between physical activity and the total or individual types of aggressiveness, deviant behavior and self-confidence. There is a statistically significant positively low correlation between the times spent at the computer desk on work days and physically manifested aggressiveness, and there is statistically significant negative low correlation between the time spent studying and deviant behavior within the whole group of respondents.
\end{abstract}

Key words: Physical Activity, Aggressiveness, Deviant Behavior, Self-Confidence, Adolescents

\section{Introduction}

An attitude exists that if the game is recognized as an activity of social and psychological significance in the process of human development, it means that this type of activity is an ancestor of the very culture (Huizinga, 1970), i.e. an ancestor of civilization itself (Mandell, 1984). Sport, as a segment of more broad space of playing, being significant in the life and development of the individual person as well as the society the person belongs to, is recognized as far back as the time of Ancient Greece (Hyland, 1990). Pieces of evidence about the existence of sports activities have reached to us from other archaic cultures as well, and not only from the ancestors of western civilization (Mandell, 1984). Those particular authors mention also about existence of sports activities and games and their importance in ancient Chinese and Indian civilizations.

If we take into consideration the short history of scientific attention towards physical activity and sport, we should not be surprised by the fact that the interdisciplinary subjects relevant to sport were either discussed or not discussed at all. One particular issue that have never been focused for a profound research is the impact of physical and sports activity on the self-esteem, aggressiveness and deviant behavior among children and young people (Stark, Kent, \& Finke, 1987; Stevenson, 1985).

For a considerable amount of time, recreation has been seen as an effective approach of recreation (Aguilar, 1986, 1987; Collingwood \& Engelsgjerd, 1977; Hormachea \& Hormachea,

\section{Montenegro}

Sport

\section{Correspondence:}

\section{G. Georgiev}

University St. Cyril and Methodius, Faculty for Physical Education, Sport, and Health, Dimče Mirčev 3, 1000, Skopje, North Macedonia

E-mail: georgigeorgiev63@yahoo.com 
1983; Krichbaum \& Alston, 1991; Munson, 1991; Segrave, 1982, 1983). At least two special scientific journal editions in the fields of examining the leisure time and recreation are dedicated to the topic of therapeutic recreation in juvenile reformative society (Jewell, 1977; Orton, 1977). The articles contain too much theoretical speculations and insufficiency of empiric and scientific data and assessments of actual programs and activities.

When it comes to the effectiveness of rehabilitation, there can be pointed that the existing literature on recreation and physical activity is not of help to explain the relatively unconvincingly thin results related to the dependence between taking part in sport and the process of socialization. Yet in literature - both theoretical and empiric - exists a common consent that recreational-reformative programs are necessary and useful both for preventive and rehabilitation purposes. If the recreational process is able to achieve its ultimate purpose - to fill up the leisure time in a productive way - then we possess a massive option of working on preventing delinquents and potential delinquents from misusing their free time.

Concerning the prevention and the proof about the effectiveness of community recreational programs in urban environments with quite frequent situations of deviant/delinquent behavior (Elliott, 1963; Lutzin \& Orem, 1967; Todd, 1941; United States Department of Justice, 1981; Wylie, 1960, 1965), there is a certain amount of positive evidence (Burns, 1907; Shanas, 1942; Truxal, 1929).

The aim of the present research is the explore the impact of physical and sports activities on the aggressive, deviant behavior and self-confidence among schoolchildren aged from 11 to 15 .

\section{Methods}

Subjects

The research was conducted on a sample of 177 Macedonian adolescents, selected by random choice from several primary schools in the city of Skopje. The average age of the respondents was 12.4 years.

The research was conducted from mid-April to mid-May 2016. Previously the principals of all primary schools that were involved in the research had been sent a letter introducing the objectives of the research. The research was carried out in cooperation with professors of physical education and psychological- pedagogical offices, in schools where they existed. The surveying was carried out in classrooms at special classes using proper organization of work appropriate for such researches. The study protocol was performed following the ethical principles by the guidelines of the Declaration of Helsinki (World Medical Association, 2001).

\section{Instrument for Assessing}

Within the research the time spent in the physical activity is rated by means of the instrument for assessing the physical acti- vity - Physical Activity Questionnaire (Elementary School), constructed by Kowalski and Crocker (2001). Sedentary habits are assessed according to the scale that is a segment of Health Behavior in School-aged Children (HBSC) study protocol (Currie et al., 2000). The respondents aresked to answer the question about the length of time they spend with sedentary activities. The questions were asked for a usual weekday and weekend day separately. Aggressiveness measure from the Questionnaire A - 87 (Žužul, 1989 consists of 15 items of different situations with five possible responses. The possible responses or reactions are the five most frequent forms of aggressive responses: a) verbal manifest aggression (VM); b) physical manifest aggression (PHM); c) indirect aggression (IND); d) verbal latent aggression (VL), and e) physical latent aggression (PHL). Deviant Behavior measure from the Denver Youth Survey is a seven-item scale (Institute of Behavioral Sciences, 1987), which asks participants to report how many of their friends have engaged in delinquent behaviors (e.g., hitting or threatening to hit someone, damaging or destroying property, drinking alcohol) in the past year. Self-esteem was measured with five items from the Rosenberg Self Esteem Scale (Rosenberg, 1965).

\section{Statistical Analysis}

The analysis was performed by using the Statistical Pack-age for Social Sciences (SPSS) version 20.0. The results obtained from the research are statistically processed and each variable is with individually calculated basic descriptive statistic parameters: arithmetical mean, standard deviation, a bottom and top limit of the results ( $\min$ - max), coefficient of symmetry - skewness, coefficient of flatness - kurtosis. The relation between the applied variables is determined by the use of Pearson's coefficient of correlation (R).

\section{Results}

Examination of Table 1 denotes the fact that the respondents' results of Skewness demonstrate positive asymmetry with the variables of physical manifest aggression (PHM), indirect aggressiveness (IND), verbal latent aggressiveness (VL), physical latent aggressiveness (PHL), summary aggressiveness (Total aggressiveness) and deviant behavior. With the rest of variables Skewness varies within the acceptable limits $(-1$ to +1$)$. The values of Kurtosis show that most variables demonstrate platykurtic (flatness of the curve), namely there is dispersion of results with most of variables. It is the variable of deviant behavior alone that shows a marked leptokurtic.

Aiming to establish the existence of statistically significant correlation between the physical activity and total and individual types of self-esteem, aggressiveness and deviant behavior, there are calculated Pearson's coefficients of correlation.

Table 1. Basic descriptive statistic parameters of variables for assessing physical activity, sedentary habits, aggressiveness A-87, delinquent behavior and self-confidence

\begin{tabular}{|c|c|c|c|c|c|c|}
\hline & Minimum & Maximum & Mean & SD & Skewness & Kurtosis \\
\hline Physical activity & 1,40 & 4,80 & 3,44 & 0,68 & $-0,07$ & $-0,61$ \\
\hline Weekday television & 1,00 & 5,00 & 1,67 & 0,75 & 0,97 & 1,02 \\
\hline Weekend television & 1,00 & 4,00 & 1,87 & 0,73 & 0,31 & $-0,79$ \\
\hline Weekday PC & 1,00 & 3,00 & 1,55 & 0,71 & 0,91 & $-0,47$ \\
\hline Weekend PC & 1,00 & 3,00 & 1,91 & 0,78 & 0,17 & $-1,35$ \\
\hline Time spent in learning & 1,00 & 5,00 & 2,14 & 0,80 & 0,81 & 1,70 \\
\hline VM aggressiveness & 15,00 & 70,00 & 31,48 & 12,32 & 0,76 & 0,01 \\
\hline
\end{tabular}


(continued from previous page)

\begin{tabular}{lcccccc}
\hline & Minimum & Maximum & Mean & SD & Skewness & Kurtosis \\
\hline PHM aggressiveness & 15,00 & 62,00 & 23,97 & 10,37 & 1,44 & 1,47 \\
IND aggressiveness & 15,00 & 61,00 & 23,32 & 9,04 & 1,66 & 3,10 \\
VL aggressiveness & 15,00 & 63,00 & 27,65 & 11,35 & 1,08 & 0,64 \\
PHL aggressiveness & 15,00 & 66,00 & 23,62 & 10,10 & 1,53 & 2,76 \\
Total aggressiveness & 14,80 & 59,80 & 25,67 & 9,45 & 1,26 & 1,49 \\
Deviant Behavior Scale & 8,00 & 35,00 & 11,40 & 4,00 & 2,25 & 7,63 \\
Self-esteem & 1,00 & 5,00 & 3,87 & 0,73 & $-0,98$ & 1,61 \\
\hline
\end{tabular}

Note: VM - verbal manifest, PHM - physical manifest, IND - indirect, VL - verbal latent, PHL - physical latent

Examining Table 2 shows that the calculated coefficients of correlation are explicitly low and there is no statistically significant correlation of the physical activity with the total and individual types of aggressiveness, deviant behavior and self-confidence.
Aiming to establish the existence of statistically significant correlation of sedentary habits with the total and individual types of aggressiveness, deviant behavior and self-confidence, there are additionally calculated Pearson's coefficients of correlation.

Table 2. Coefficients of correlation between the physical activity and Aggressiveness, Deviant Behavior and Self-esteem

\begin{tabular}{lcccccccc}
\hline & VM & PHM & IND & VL & PHL & Total & DBVS & Self-esteem \\
\hline $\begin{array}{l}\text { Physical } \\
\text { activity }\end{array}$ & $-0,032$ & 0,089 & 0,034 & 0,017 & 0,101 & 0,042 & 0,019 & 0,012 \\
\hline
\end{tabular}

Note: VM - verbal manifest aggressiveness; PHM - physical manifest aggressiveness; IND - indirect aggressiveness; VL - verbal latent aggressiveness; PHL - physical latent aggressiveness; Total - total aggressiveness; DBVS - deviant behavior scale

Observing Table 3, we can see that there is a statistically si- $\quad$ deviant behavior $(r=-0,212 ; \mathrm{p}<0,05)$. gnificant positively low correlation of the time spent working on a computer in working days with physically manifested aggressiveness $(r=0,218 ; p<0,05)$, and statistically significant negative correlation is established between the time spent studying and

Aiming to establish the existence of statistically significant correlation between the deviant behavior and self-confidence on one hand, and aggressive behavior on the other hand, Pearson's coefficients of correlation are calculated.

Table 3. Coefficients of cross-correlation between sedentary habits and total and individual types of aggressiveness, deviant behavior and self-confidence

\begin{tabular}{lcccccccc}
\hline & VM & PHM & IND & VL & PHL & Total & DBVS & Self-esteem \\
\hline Weekday television & 0,074 & 0,162 & 0,009 & 0,051 & 0,091 & 0,088 & 0,177 & 0,063 \\
Weekend television & 0,151 & 0,095 & 0,041 & 0,084 & 0,035 & 0,096 & 0,048 & 0,015 \\
Weekday PC & 0,135 & 0,218 & 0,144 & 0,119 & 0,164 & 0,172 & 0,086 & $-0,021$ \\
Weekend PC & 0,162 & 0,160 & 0,146 & 0,112 & 0,111 & 0,154 & 0,126 & $-0,011$ \\
Time spent in learning & $-0,080$ & $-0,067$ & $-0,012$ & $-0,004$ & 0,026 & $-0,033$ & $-0,212$ & $-0,120$ \\
\hline
\end{tabular}

Note: VM - verbal manifest aggressiveness; PHM - physical manifest aggressiveness; IND - indirect aggressiveness; VL - verbal latent aggressiveness; PHL - physical latent aggressiveness; Total - total aggressiveness; DBVS - deviant behavior scale

Examining Table 4, it is obvious that there is a statistically si- tion demonstrates the deviant behavior and indirect aggressivenegnificant positive correlation between deviant behavior and verbal ss. On the other hand, there can be noticed that, in this sample of manifest aggressiveness $(r=0,551 ; \mathrm{p}<0,00)$, deviant behavior and respondents, there is no statistically significant correlation between verbal latent aggressiveness $(r=0,428 ; p<0,00)$. The highest correla- self-confidence and total and individual types of aggressiveness.

Table 4. Coefficients of cross-correlation between the deviant behavior and self-confidence on one hand, and aggressive behavior on the other hand

\begin{tabular}{lcccccc}
\hline & VM & PHM & IND & VL & PHL & Total \\
\hline DBVS & 0,455 & 0,551 & 0,558 & 0,428 & 0,431 & 0,535 \\
Self-esteem & $-0,101$ & $-0,084$ & $-0,136$ & $-0,136$ & $-0,141$ & $-0,133$ \\
\hline
\end{tabular}

Note: VM - verbal manifest aggressiveness; PHM - physical manifest aggressiveness; IND - indirect aggressiveness; VL - verbal latent aggressiveness; PHL - physical latent aggressiveness; Total - total aggressiveness; DBVS - deviant behavior scale 


\section{Discussion}

The ruining effect that physical non-activity has on health brings forth the need of better understanding the models and determinants that would stimulate boosting physical activities among schoolchildren. A considerable number of study papers point at the decrease in physical activities among adolescents with further decline in the years of early maturity. A large number of studies on that topic are completed in many countries worldwide, but the question is whether the results obtained from these researches can be generally applied to the Macedonian population of adolescents (Gordon-Larsen, McMurray, \& Popkin, 2000). In fact, the comprehension of factors involving reduction in physical activity among adolescents is of a vital importance for the development of effective programs and strategies in promoting the physical activity among that group of population.

The present research, carried on the described sample of respondents and the given age, does not establish a presence of statistically significant correlation between physical activity, on the one hand, and the total and individual types of aggressiveness, deviant behavior and self-confident, on the other hand. Further, the results of the research provide indications of correlation existing between the time spent working on a computer in school days and aggressiveness (physically manifested aggressiveness) and deviant behavior. Longitudinal research exploring excessive TV watching in early childhood has suggested that large amounts of exposure to electronic media in early childhood may be related to symptoms/diagnosis of attention deficit/ hyperactivity disorder (ADHD) - see Barlett, Anderson, \& Swing (2009) for a review. In turn, ADHD may be related to delinquency (Pratt, $\mathrm{Cu}-$ llen, Blevins, Daigle, \& Unnever, 2002); however, some research has suggested otherwise (Stevens \& Mulsow, 2006). ADHD may be also indirectly related to delinquency through other potentially enabling factors, such as personal strains (Johnson \& Kercher, 2007). This finding also supports research in that excessive TV viewing may be associated with risky behavior; however, there is evidence to suggest that parental regulation may be an important factor in this relationship (Nelson \& Gordon-Larsen, 2006). Schoolchildren of both genders who spend more time working on a computer show greater aggressiveness and deviant behavior. Also, there is a positive correlation between the deviant behavior and the total and individual types of aggressiveness, whereas statistically significant correlation is not established between the deviant behavior and self-confidence.

The worrying moment is the fact that schoolchildren of both genders spend a great amount of their free time watching TV, or working on computers. World Health Organization (De Onis et al., 2007) strongly recommend that "children and young people should not spend more than two hours daily in watching TV or working on a computer (surfing, chatting or playing video games)".

The characteristic feature of the present research is the application of A-87 questionnaire. The results obtained from the research indicate that the average discourse in aggressiveness within that sample of respondents is about half a standard deviation of the existing norms, both in total and individual types of aggressive behavior, which suggests that adolescents have certain inclination towards aggressive behavior (Mitrofan, Paul, \& Spencer, 2009; van Egmond-Frohlich, Weghuber, \& de Zwaan, 2012; Robertson, McAnally, \& Hancox, 2013). In support of that stands the arch of the curve showing positive asymmetry, a greater number of the results being in the zone of higher ones. The higher aggressiveness obtained with that sample of respondents in contrast to matured people can be explained with the approach of the respondents into the adolescent period, when young people always look for being themselves and try to build their identity, so aggressiveness is quite often a tool to struggle for one's position. Despite the fact that adolescents possess a greater range of strategies in solving conflicts as compared to children, yet they are not so socially skilled as compared to adults. Moreover, the civil law tolerates to some extent the aggressiveness with persons younger than the age of 18 years, whereas legal penalty measures against adults are far more restrictive, so they are willing to control aggressive expressions.

On the base of the obtained results, the following conclusions can be drawn: there is no statistically significant correlation between the physical activity and the total and individual types of aggressiveness, deviant behavior and self-confidence. There is a statistically significant positively low correlation between the times spent working on the computer at work and physically manifested aggressiveness; and statistically significant negative low correlation between the times spent studying and deviant behavior.

\section{Acknowledgements}

There are no acknowledgements.

\section{Conflict of Interest}

The authors declare that there are no conflicts of interest.

Received: 18 May 2019 | Accepted: 20 August 2019 | Published: 11 October 2019

\section{References}

Aguilar, T.E. (1986). Recreation: An untapped resource. Corrections Today, 48(2), 173-178.

Aguilar, T.E. (1987). Effects of a leisure education program on expressed attitudes of delinquent adolescents. Therapeutic Recreation Journal, 21 (4), 43-51.

Barlett, C.P., Anderson, C.A., \& Swing, E.L. (2009). Video Game Effects-Confirmed, Suspected, and Speculative. Simulation \& Gaming, 40(3), 377-403. doi: $10.1177 / 1046878108327539$

Burns, T. (1907). Relation of playgrounds to juvenile delinquency. Charities, 21, 25-31.

Collingwood, T.R., \& Engelsgjerd, M. (1977). Physical Fitness, Physical Activity, and Juvenile Delinquency. Journal of Physical Education and Recreation, 48(6), 23-23. doi: 10.1080/00971170.1977.10621069

Currie, C., Griebler, R., Inchley, J., Theunissen, A., Molcho, M., Samdal, O., \& Dür, W. (2010). Health Behaviour in School-aged Children (HBSC) study protocol: background, methodology and mandatory items for the 2009/10 survey. Edinburgh: CAHRU.

De Onis, M., Onyango, A.W, Borghi, E., Siyam, A., Nishida, C., \& Siekmann, J. (2007) Development of a WHO growth reference for school-aged children and adolescents. Bulletin of the World Health Organization, 85(09), 660-667. doi: 10.2471/BLT.07.043497

Elliott, M.A. (1963). Group therapy in dealing with juvenile and adult offenders. Federal Probation, 27(4), 48-54.

Gordon-Larsen, P., McMurray, R.G., \& Popkin, B. M. (2000). Determinants of adolescent physical activity and inactivity patterns. Pediatrics, 105(6), e83. doi:10.1542/peds.105.6.e83

Hormachea, M., \& Hormachea, C. (1983). Recreation and the youthful and adult offenders. In Stein, T.A., \& Sessoms, H.D. (Eds.), Recreation and special populations (105-134), London: Allyn and Bacon, Inc.

Huizinga, J. (1970). Homo ludens: A study of the play element in culture. London: Temple Smith.

Hyland, D.A. (1990). Philosophy of sport. New York: Paragon House.

Institute of Behavioral Sciences. (1987). Youth Interview Schedule: Denver Youth Survey. Boulder, CO: University of Colorado, 1987.

Jewell, D.L. (1977). Maximum security: Some obstacles to meaningful recreational programming. Therapeutic Recreational Journal, 11, 185-188.

Johnson, M.C., \& Kercher, G.A. (2007). ADHD, strain, and criminal behavior: a test of general strain theory. Deviant Behavior, 28(2), 131-152. doi: 10.1080/01639620601130992

Kowalski, K.C., \& Crocker, P.R.E. (2001). Development and validation of the Cop ing Function Questionnaire for adolescents in sport. Journal of Sport \& Exercise Psychology, 23(2), 136-155. doi: 10.1123/jsep.23.2.136 
Krichbaum, D., \& Alston, M.A. (1991). Youth restitution \& recreation: A successful mix. Parks and Recreation, 26(3), 42-45.

Lutzin, S.G., \& Orem, R.C. (1967). Prevention through recreation. In Amos, W.A. \& Wellford, C.F. (Eds.), Delinquency Prevention: Theory and Practice (150 170). Englewood Cliffs, New Jersey: Prentice-Hall, Inc.

Mandell, R.D. (1984). Sport: A cultural history. New York: Columbia University Press.

Mitrofan, O., Paul, M., \& Spencer, N. (2009). Is aggression in children with behavioural and emotional difficulties associated with television viewing and video game playing? A systematic review. Child: care, health and development, 35(1), 5-15. doi: 10.1111/j.1365-2214.2008.00912.x

Munson, W.W. (1991). Juvenile delinquency as a societal problem and social disability: Thetherapeutic recreator's role as ecological change agent. Therapeutic Recreation Journal, 25(2), 19-30.

Nelson, M. C., \& Gordon-Larsen, P. (2006). Physical activity and sedentary behavior patterns are associated with selected adolescent health risk behaviors. Pediatrics, 117(4), 1281-1290.

Orton, D.J. (1977). An investigation of the past, present and future recreation pursuits of adult inmates in two lowa correctional institutions. Therapeutic Recreation Journal, 2, 66-69.

Pratt, T. C., Cullen, F., Blevins, K., Daigle, L., \& Unnever, J. (2002). The relationship of attention deficit hyperactivity disorder to crime and delinquency: A meta-analysis. International Journal of Police Science and Management, 4(4), 344-360. doi: 10.1350/ijps.4.4.344.10873

Robertson, L.A., McAnally, H.M., \& Hancox, R.J. (2013). Childhood and adolescent television viewing and antisocial behavior in early adulthood. Pediatrics, 131(3), 439-446

Rosenberg, M. (1965). Society and the adolescent self-image. Princeton, New Jersey: Princeton University Press.

Segrave, J.O. (1982). An investigation into the relationship between participation in interscholastic athletics and delinquent behavior. Unpublished Doctoral Dissertation. Tempe, Arizona: Arizona State University.

Segrave, J.O. (1983). Sport and juvenile delinquency. Exercise and Sport Sciences Reviews, 11(1), 181-209.
Shanas, E. (1942). Recreation and delinquency: A study of five selected Chicago communities. Chicago: University of Chicago Press.

Stark, C.L., Kent, L., \& Finke, R. (1987). Sports and delinquency. In Gottfredson, M.R., \& Hirschi, T. (Eds.), Positive criminology (115-124). Newbury Park, California: Sage Publications.

Stevens, T., \& Mulsow, M. (2006). There is no relationship between television ex posure and symptoms of attention-deficit/hyperactivity disorder. Pediatrics, $117(3), 665-672$.

Stevenson, C.L. (1985). College athletes and "character": The decline and fall of socialization research. In Chu, D.B., Segrave, J.O., \& Becker, B.J. (Eds.) Sport and higher education (249-266). Champaign, Ilinois: Human Kinetics Publishers, Inc.

Todd, A.J. (1941). Recreation and delinquency. Federal Probation. 5(4), 19-24.

Truxal, A.G. (1929). Outdoor recreation legislation and its effectiveness. New York: Columbia University Press.

United States Department of Justice. (1981). Executive summary of the national evaluation of prevention final report. San Francisco: National Council on Crime and Delinquency Research Center.

Van Egmond-Fröhlich, A.W., Weghuber, D., \& de Zwaan, M. (2012). Association of symptoms of attention-deficit/hyperactivity disorder with physical activity, media time, and food intake in children and adolescents. PloS one, 7(11), e49781.

World Medical Association. (2001). Declaration of Helsinki: Ethical principles for medical research involving human subjects. Bulletin of the World Health Organization, 79(4), 373-374.

Wylie, J.A. (1960). Recreation and delinquency. The Journal of Education 143, 14-20.

Wylie, J.A. (1965). Recreation and juvenile delinquency. Education, 86, 86-90.

Žužul, M. (1989). Agresivno ponašanje: psihologijska analiza. [Aggressive behavior: Psychological analysis - In Croatian.] Zagreb: Radna zajednica Republičke konferencije Saveza socijalističke omladine Hrvatske. 